\title{
The Use of Biofeedback in the Treatment of Chronic Dysphagia in Stroke Patients
}

\author{
H.C.A. Bogaardt W. Grolman W.J. Fokkens \\ Department of Otorhinolaryngology, Academic Medical Center, University of Amsterdam, \\ Amsterdam, The Netherlands
}

\section{Key Words}

Dysphagia $\cdot$ Speech-language pathology $\cdot$ Stroke

\begin{abstract}
Objective: To evaluate the efficacy of the use of surface electromyographic feedback in the treatment of stroke patients with chronic dysphagia. Patients and Methods: Data of 11 consecutive patients with chronic dysphagia after stroke were analyzed. Our patients were treated for dysphagia with surface electromyography as biofeedback as adjunct to normal exercises. All patients suffered from dysphagia after stroke. The average time after onset was 31.1 months. All patients had been previously treated by speech therapists without success. Functional swallowing was estimated using the Functional Oral Intake Scale (FOIS). At the start of the treatment 8 patients were tube dependent (FOIS $\leq 4$ ). Three patients were on an oral diet, but with restrictions (FOIS $\geq 5$ ). Results: The patients were treated on average seven 7 times. The time between the first and last treatment session was on average 76.1 days (SD \pm 44.0 ; range $=29-168$ ). Before treatment the average FOIS was 2.6 (SD \pm 2.3 ) and after treatment 5.6 (SD \pm 1.6 ). The median scores improved from 1 to 6 , showing a significant and clinically relevant improvement $(z=$ -2.820 : $p<0.01$ ) in swallowing function. In 6 of initially 8 patients with percutaneous enteral gastrostomy tubes, the feeding tube could be removed after treatment. Conclu-
\end{abstract}

sion: Our data suggest that the use of surface electromyography as biofeedback in the treatment of chronic dysphagia after stroke could be an effective adjunct to standard therapy for swallowing disorders in 11 patients.

Copyright $\odot 2009$ S. Karger AG, Basel

\section{Introduction}

In the literature, stroke (ischaemic infarct or bleeding in the brain) is often described as one of the main causes of dysphagia. About $50 \%$ of the stroke patients will suffer from swallowing disorders like coughing and choking when eating and drinking [1]. In many patients the swallowing function will recover in a short period (2 months) of time [2], but in a small group of patients total recovery of the swallowing function can take many months to several years [3]. If the swallowing function fails to recover, the patients have to be fed through a feeding tube [percutaneous enteral gastrostomy (PEG) tube] to maintain a normal nutritional status. A Canadian study [4] suggests that $1.25 \%$ of all stroke patients will be in need of parenteral nutrition (tube feeding). Elia et al. [5] estimate that the incidence of stroke patients who are fed over a PEG tube for over a period of 1 year is $1.7 \%$ in the UK. More recently a study [6] showed that $55 \%$ of the stroke patients who had a PEG tube

\section{KARGER}

Fax +4161306 1234 E-Mail karger@karger.ch www.karger.com
(C) 2009 S. Karger AG, Basel

1021-7762/09/0614-0200\$26.00/0

Accessible online at:

www.karger.com/fpl
H.C.A. Bogaardt, MSc

Department of Otolaryngology-Head and Neck Surgery/D2-313

Academic Medical Center, PO Box 22660

NL-1100 DD Amsterdam (The Netherlands)

Tel. +31 20566 3722, Fax +31 20566 9068, E-Mail h.c.bogaardt@amc.uva.nl 


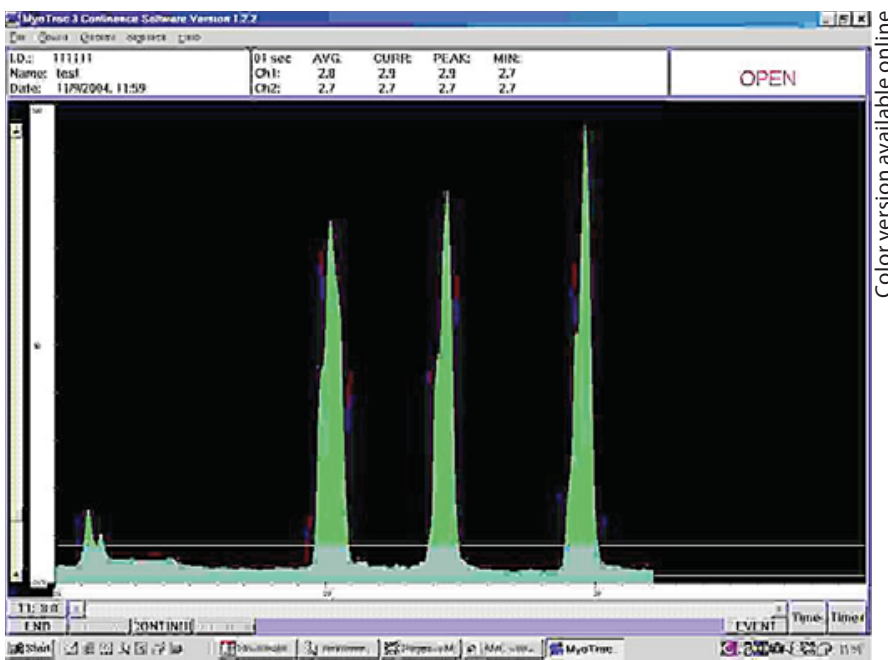

Fig. 1. Characteristics of normal swallowing.

placed, still were dependent on tube feeding at a followup 2 years after stroke.

Publications like those by Crary [7] and Huckabee and Cannito [8], however, show that the treatment of patients with severe and chronic dysphagia with surface electromyography (sEMG) as biofeedback can be effective. The use of sEMG as a biofeedback tool in the treatment of dysphagia is relatively new for speech therapists. Although other allied health professionals, like physiotherapists, have already used this biofeedback tool for several decades, the first application of sEMG in speech therapy is estimated around 1990, following the first publication by Crary in 1995 [8].

Biofeedback is defined as 'the technique of using equipment (usually electronic) to reveal to human beings some of their internal physiological events, normal and abnormal, in the form of visual and auditory signals, in order to teach them to manipulate these otherwise involuntary or unfelt events by manipulating the displayed signals' [9]. The rationale is thus that if a patient sees his muscle activity, rather than just feeling his muscles contract, he will be able to contract his muscles more fiercely and therefore be able to train his muscles faster. The use of sEMG biofeedback has proven to be effective in other professions and patient groups. Although there are only few meta-analyses of studies or reviews published on the use of sEMG as a biofeedback tool in the treatment of stroke patients, the trend of the published meta-analyses and reviews directs to a positive treatment effect of EMG as biofeedback in stroke patients $[10,11]$.

Biofeedback in the Treatment of Chronic

Dysphagia in Stroke Patients

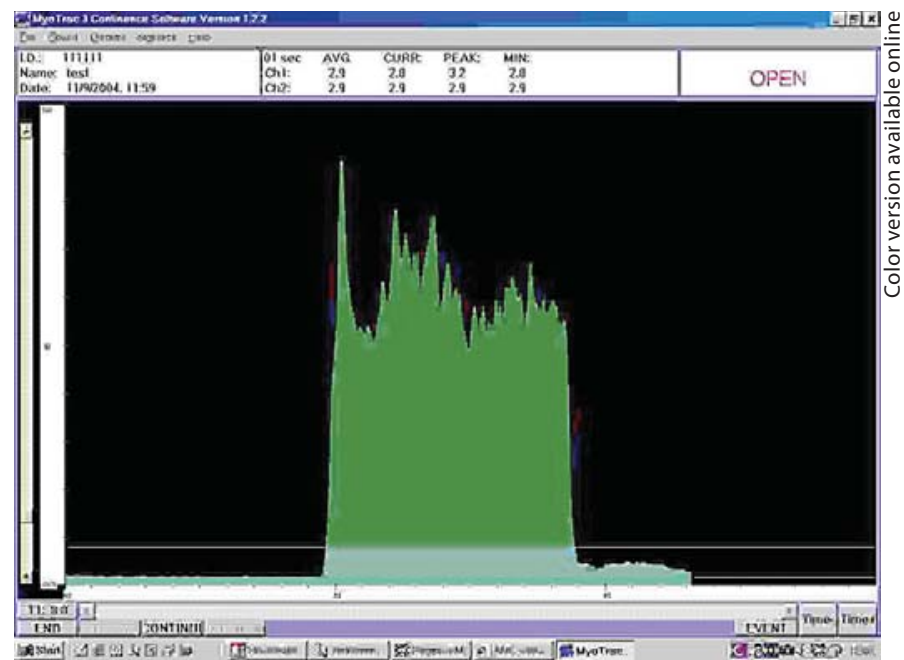

Fig. 2. SEMG trace during a Mendelsohn maneuver.

When using sEMG as biofeedback in dysphagia therapy, electrodes are placed under the chin, between the front of the mandible and the hyoid, thus recording the muscle activity in the submental muscles (m. stylohyoideus, $\mathrm{m}$. mylohyoideus, $\mathrm{m}$. digastricus). During swallowing the larynx is elevated and moved forward by contraction of the supralaryngeal, suprahyoidal and submental muscles [12]. In their study Ding et al. [13] established a good correlation between sEMG measurements of the submental muscles and swallowing. Figure 1 shows the EMG curve of 3 swallows in a normal, healthy person. On the horizontal axis the time frame is $30 \mathrm{~s}$, the vertical axis shows the electrical activity (measured in microvolt) of the submental muscles.

In the treatment of dysphagia with sEMG as an adjunct, therapy focuses on repeatedly making the Mendelsohn maneuver. This maneuver was designed as a compensatory swallowing technique to clear residue from the pharynx [14] but has also shown to be effective as a rehabilitative exercise for restoring swallowing function [8]. The Mendelsohn maneuver as a rehabilitative exercise may result in a better laryngeal elevation and coordination during swallowing [15] and is also considered to contribute to a better pharyngeal contraction [16]. A patient is instructed to hold his breath and make a 'long swallow' or to keep his larynx elevated for several seconds following a swallow.

Our patients were instructed to make a modified Mendelsohn's maneuver, where they prolong the laryngeal excursion to a maximum of $10 \mathrm{~s}$, instead of $2-3 \mathrm{~s}$ as in the

Folia Phoniatr Logop 2009;61:200-205 
Table 1. Patient data and diagnosis

\begin{tabular}{|c|c|c|c|c|c|c|}
\hline Patient & Sex & $\begin{array}{l}\text { Age } \\
\text { years }\end{array}$ & Diagnosis ${ }^{1}$ & $\begin{array}{l}\text { Months } \\
\text { after stroke }\end{array}$ & Complaints and pathophysiology & Diet \\
\hline 1 & M & 69.9 & $\begin{array}{l}\text { left-sided } \\
\text { lacunar infarct }\end{array}$ & 24 & coughing on thin liquids: 10 times a day, food gets stuck ${ }^{4}$ & oral diet \\
\hline 2 & M & 71.1 & $\begin{array}{l}\text { Wallenberg } \\
\text { syndrome }\end{array}$ & 10 & $\begin{array}{l}\text { frequent coughing on saliva swallows, silent aspiration of thin } \\
\text { liquids }^{2} \text {, reduced laryngeal excursion }{ }^{2}, \text { residue piriform sinuses }\end{array}$ & nil-by-mouth \\
\hline 3 & M & 58.8 & $\begin{array}{l}\text { Wallenberg } \\
\text { syndrome }\end{array}$ & 5 & $\begin{array}{l}\text { has to spit out saliva, frequent coughing on saliva swallows, } \\
\text { aspiration of thin liquids, reduced pharyngeal contraction }{ }^{2}\end{array}$ & nil-by-mouth \\
\hline 4 & M & 49.0 & left cortical stroke & 7 & $\begin{array}{l}\text { coughing on thin liquids, food gets stuck, cricopharyngeal } \\
\text { impression }^{2}\end{array}$ & oral diet \\
\hline 5 & M & 64.6 & brainstem CVA & 10 & $\begin{array}{l}\text { frequent coughing on saliva, absent pharyngeal contraction, } \\
\text { reduced laryngeal excursion }{ }^{2}\end{array}$ & nil-by-mouth \\
\hline 6 & $\mathrm{~F}$ & 54.0 & $\begin{array}{l}\text { Multi-trauma/ } \\
\text { brain-injury }\end{array}$ & 13 & $\begin{array}{l}\text { frequent coughing on saliva, } 4 \text { times aspiration pneumonia, } \\
\text { saliva stasis in piriform sinuses, silent aspiration }{ }^{3}\end{array}$ & $\begin{array}{l}\text { nil-by-mouth, } \\
\text { with minimal } \\
\text { attempts }\end{array}$ \\
\hline 7 & M & 66.5 & $\begin{array}{l}\text { left-sided } \\
\text { lacunar infarct }\end{array}$ & 24 & has to spit out saliva, tries to swallow yoghurt ${ }^{4}$ & $\begin{array}{l}\text { nil-by-mouth, } \\
\text { with minimal } \\
\text { attempts }\end{array}$ \\
\hline 8 & M & 71.4 & brainstem CVA & 72 & $\begin{array}{l}\text { has to spit out saliva, frequent coughing, no pharyngeal } \\
\text { response when swallowing, silent aspiration on every swallow }{ }^{2}\end{array}$ & nil-by-mouth \\
\hline 9 & M & 55.5 & $\begin{array}{l}\text { Wallenberg } \\
\text { syndrome }\end{array}$ & 145 & $\begin{array}{l}\text { coughing on saliva several times a day, food gets stuck } \\
\text { in throat, no aspiration with thin liquids }{ }^{2}\end{array}$ & oral diet \\
\hline 10 & M & 57.4 & brainstem CVA & 18 & $\begin{array}{l}\text { patient with tracheotomy, inflated cuff, spits out saliva, saliva } \\
\text { stasis in piriform sinuses, silent aspiration of thin liquids }{ }^{3}\end{array}$ & nil-by-mouth \\
\hline 11 & M & 59.5 & brainstem CVA & 8 & $\begin{array}{l}\text { coughing on thin and thick liquids, delayed pharyngeal response, } \\
\text { no laryngeal excursion, absent pharyngeal contraction }{ }^{2}\end{array}$ & nil-by-mouth \\
\hline & & 61.1 & & & & \\
\hline
\end{tabular}

CVA $=$ Cerebrovascular accident.

${ }^{1}$ Diagnosis as mentioned on referral. ${ }^{2}$ As diagnosed by a radiologist on videofluoroscopy. ${ }^{3}$ As diagnosed with FEES. ${ }^{4}$ No videofluoroscopy or FEES performed.

original maneuver. The rationale for this modification is that we consider the Mendelsohn maneuver to be an isometric exercise, and thus the exercise should be performed either fast and often or at a slower pace with a prolonged contraction [17]. This same principle is used in another exercise for dysphagic patients (Shaker's head tilt exercise), where faster and slower exercises are combined [18]. Whereas figure 1 shows the characteristics of a normal swallow (a short peak with a total duration of about $2 \mathrm{~s}$ ), figure 2 presents the sEMG trace of a Mendelsohn maneuver for a period of $10 \mathrm{~s}$. During dysphagia therapy the patient is asked to make several Mendelsohn maneu- vers. While watching the sEMG signal on a computer monitor, the patient has an immediate feedback of his swallowing performance.

\section{Patients and Methods}

Efficacy of sEMG as Biofeedback in Patients with Chronic Neurogenic Dysphagia

As a pilot study, to establish data for a further randomized clinical trial, the data on chronic dysphagic stroke patients, who were treated in our department with SEMG as an adjunct to dysphagia therapy, were analyzed. 
Patients

Retrospectively the data of 11 consecutive patients with chronic dysphagia after stroke, who were treated with sEMG as biofeedback between 2002 and 2004, were analyzed.

Our patients (10 males, 1 female) aged from 54.0 to 71.4 years (mean $=61.1, \mathrm{SD}= \pm 7.6$ ) were treated for dysphagia with sEMG as biofeedback as adjunct to normal exercises. All patients suffered from dysphagia after stroke (10 had brainstem lesions, 1 had a left cortical lesion) and had received rehabilitative treatment in various rehabilitation facilities. Although some patients still had physiotherapy at these centres in a day care setting, most of them were discharged of further therapy. All patients lived at home with their spouses. The average time between the onset of stroke and the first treatment session at our clinic was 30.6 months $(\mathrm{SD}= \pm 42.4$; range $=5.0-145.0$ ), and all patients had previously been treated by a speech therapist for their swallowing problems, without success.

The functional swallowing ability of each patient was estimated using the Functional Oral Intake Scale (FOIS), a 7-point ordinal scale reflecting patient report of food/liquid safely ingested by mouth on a consistent basis [19], see table 2 .

At the start of the treatment 8 patients were fully tube dependent for nutrition (i.e. FOIS $\leq 3$ ). The other 3 patients were already capable of eating and drinking but had restrictions and limitations to certain consistencies (i.e. FOIS $\geq 4$ ). The patients had an average score of 2.6 ( $\mathrm{SD} \pm 2.3$ ) on the FOIS before starting the treatment with sEMG biofeedback. The median pretreatment score was 1 .

Methods

The treatment consisted of maintaining a swallow for 8-10 s (i.e. modified Mendelsohn's maneuver) every $30 \mathrm{~s}$ for a period of
20 min per treatment session. The swallowing activity was visualized by the use of sEMG of the submental muscles, using MyoTrac III equipment (Thought Technology, Canada) on a standard computer with a 17 -inch monitor.

Initially the patients received treatment in our clinic once a week, as the swallowing function showed improvement, the frequency of treatment was changed to 1 session biweekly. When not receiving treatment in our clinic, the patients were instructed to repeat these exercises, without the use of sEMG biofeedback, at home 2-3 times a day (in total 40-60 repetitions daily). As an alternative for sEMG biofeedback in the home setting, the patients were instructed to lay their index finger horizontally over the thyroid region so that they could feel the laryngeal movement.

Table 2. Functional Oral Intake Scale

Lev- Description

el

Nothing by mouth

Tube-dependent with minimal attempts of food or liquid

Tube-dependent with consistent oral intake of food or liquid

Total oral diet of a single consistency

Total oral diet with multiple consistencies but requiring special preparation or compensations

6 Total oral diet without special preparation but with specific food limitations

7 Total oral diet without restrictions

Table 3. Treatment data and outcomes

\begin{tabular}{|c|c|c|c|c|c|c|}
\hline Patient & Sessions & $\begin{array}{l}\text { Total days of } \\
\text { treatment }\end{array}$ & $\begin{array}{l}\text { Pretreatment } \\
\text { FOIS }\end{array}$ & $\begin{array}{l}\text { Posttreatment } \\
\text { FOIS }\end{array}$ & $\begin{array}{l}\text { Pretreatment } \\
\text { PEG }\end{array}$ & $\begin{array}{l}\text { Posttreatment } \\
\text { PEG }\end{array}$ \\
\hline 1 & 4 & 46 & 6 & 7 & no & no \\
\hline 2 & 6 & 63 & 1 & 6 & yes & no \\
\hline 3 & 7 & 56 & 1 & 6 & yes & no \\
\hline 4 & 3 & 77 & 6 & 7 & no & no \\
\hline 5 & 7 & 63 & 1 & 7 & yes & no \\
\hline 6 & 6 & 77 & 2 & 6 & yes & no \\
\hline 7 & 4 & 49 & 2 & 6 & yes & no \\
\hline 8 & 6 & 56 & 1 & $3^{\mathrm{a}}$ & yes & yes \\
\hline 9 & 4 & 29 & 6 & $9^{b}$ & no & no \\
\hline 10 & 15 & 168 & 1 & $2^{c}$ & yes & yes \\
\hline 11 & 9 & 153 & 1 & 6 & yes & no \\
\hline Mean & 6.4 & 76.1 & 2.6 & 5.6 & & \\
\hline SD & 3.3 & 44.0 & 2.3 & 1.6 & & \\
\hline Median & 6 & 63 & 1 & $6^{\mathrm{d}}$ & & \\
\hline \multicolumn{7}{|c|}{ a Patient died (MCI). } \\
\hline
\end{tabular}

Biofeedback in the Treatment of Chronic 
If a patient's swallowing clinically improved [i.e., less coughing on saliva swallowing, less spitting out of saliva or a dryer pillow in the morning (indicating that the patient swallowed his saliva during his sleep)] and the patient did not have any sign of pulmonary complications (fever, chest pain, coughing up green or yellow mucus), the patient was instructed to start swallowing small sips of water during the day in the home setting. The patient was also told to monitor his temperature daily with a thermometer and to consult his general practitioner immediately if there were signs of fever (and thus possible aspiration pneumonia).

If a patient could swallow little sips of water during the day for several weeks without any complications, a flexible endoscopic evaluation of swallowing (FEES) [20] was performed to evaluate whether the patient could also swallow other boluses safely. As FEES is available in the department, this procedure was performed on the patients prior to a change of dietary level; if clinically the swallowing had improved, i.e. they could swallow a certain viscosity for several weeks without any pulmonary problems (aspiration pneumonia), FEES was performed with other boluses to establish swallowing safety.

Statistical analysis was carried out using SPSS 12.0 (SPSS, Chicago, Ill., USA). A Wilcoxon (paired) analysis was used to detect significant changes in swallowing scores.

\section{Results}

Eight patients were treated until they reached a satisfactory level of oral intake. One patient died of a myocard infarction during his sleep before the treatment was ended, and 1 patient chose functional surgery (laryngectomy) as further treatment. Both patients had to that point benefited from the described treatment; 2- and 1-point increase on the FOIS scale, respectively. The data of these patients were included in the data analysis, according to the intention-to-treat principle. One patient stopped therapy because of complaints of dizziness during the exercises at home.

As a group, all patients were treated on average 7 times $(\mathrm{SD}= \pm 3.3$; range $=3-15)$. The time between the first and last treatment session was on average 76.1 days $(\mathrm{SD}=$ \pm 44.0 ; range $=29-168)$. After treatment the average score on the FOIS was $5.6(\mathrm{SD}= \pm 1.6)$, with a median score of 6. A Wilcoxon (paired) analysis showed a significantly and clinically relevant improvement $(\mathrm{z}=$ $-2.820, \mathrm{p}<0.01)$ in swallowing function. In the initial 8 patients with PEG tubes, the feeding tube could be removed after treatment in 6 patients, establishing a 75\% success rate. Of the 6 patients in whom the PEG tube could be removed, 3 had no limitations to their oral diet (FOIS 7) and 3 had only small limitations (FOIS 6).

Of the 3 patients who had already been on a partially oral diet prior to the treatment, 1 (initial FOIS score: 6) stopped treatment because of complaints of dizziness. The 2 other patients (FOIS 5 and FOIS 6, respectively) completed the treatment, and at discharge they had no limitations to their oral diet (FOIS 7).

From the time of the start of the treatment in our department until discharge, each patient underwent 3-4 FEES examinations. None of our patients developed aspiration pneumonia or other pulmonary complications.

\section{Discussion}

Our data support previous reports that the use of sEMG as biofeedback in the treatment of chronic dysphagia after stroke is an effective adjunct to standard therapy for swallowing disorders in these patients.

A limitation to our data is that the first patients were not treated according to a specific protocol and therefore not only had Mendelsohn maneuvers with sEMG biofeedback as a rehabilitative exercise. Some patients combined the sEMG biofeedback treatment with exercises as the Masako maneuver and the Shaker Head Tilt exercise [21]. However, as all of our patients had failed to make any progression in previous received speech therapy, where they had already tried these exercises without any success, their progression in functional swallowing can be considered more as a result of the introduction of sEMG as a biofeedback tool than as an effect of these specific exercises.

The outcome in our study differs from other articles $[7,8]$. This might be due to a different treatment intensity and treatment frequency, as the training of muscle strength and muscle coordination is considered to be dependent on the intensity and frequency of the treatment [22]. In our treatment program, patients perform the Mendelsohn maneuver for $10 \mathrm{~s}$, whereas in the Crary study patients contract their muscles less. Furthermore, in the treatment described in the articles it is often seen that also another range of rehabilitative exercises are introduced during the sessions so that any given result cannot be described with respect to the use of sEMG as biofeedback [16]. In cases where the intensity of the given treatment is discussed, it differs from article to article. Only Huckabee and Cannito [8] describe the therapy intensity rather clearly. Two articles $[7,19]$ state that patients use sEMG equipment at home while doing exercises, whereas in other studies the sEMG equipment is only used when the patient visits the institution. These differences in treatment intensity make comparisons of 
these articles and their treatment outcomes impossible.

Three patients did not end the treatment: 1 died of heart problems in his sleep, 1 stopped treatment because of problems with dizziness and 1 chose to have functional surgery (laryngectomy) as a possible solution to his inability to swallow. Their data were included in the analyses on a group level as it is unknown whether in other studies patients have dropped out of the therapy program, and if so, the reason for a possible drop-out in other articles is not clearly described. Also, deleting the data from our study would introduce a selection bias to our research.

\section{Conclusion}

To conclude, our study suggests that sEMG as biofeedback in the treatment of chronic dysphagia after stroke is an effective adjunct to standard therapy for swallowing disorders in 11 stroke patients. However, critical appraisal of existing literature and methodological limitations to our study show the need of setting up randomized controlled trials, with clear treatment protocols and treatment intensity, in this area of dysphagia treatment in the near future, to provide evidence for the efficacy and efficiency of sEMG biofeedback in the treatment of dysphagic patients.

\section{References}

1 Dogget D, Tappe K, Mitchell M: Prevention of pneumonia in elderly stroke patients by systematic diagnosis and treatment of dysphagia: an evidence-based comprehensive analysis of the literature. Dysphagia 2001;16: 279-295.

-2 Prosiegel M, Heintze M, Wagner-Sonntag E, Hannig C, Wuttge-Hannig A, Yassouridis A: Deglutition disorders in neurological patients: a prospective study of diagnosis, pattern of impairment, therapy and outcome. Nervenarzt 2002;73:364-370.

-3 Aydogdu I, Ertekin C, Tarlaci S: Dysphagia in lateral medullary infarction (Wallenberg's syndrome): an acute disconnection syndrome in premotor neurons related to swallowing activity. Stroke 2001;32:2081-2087.

-4 Teasell R, Foley N, McRae M, Finestone H: Use of percutaneous gastrojejunostomy feeding tubes in the rehabilitation of stroke patients. Arch Phys Med Rehabil 2001;82: 1412-1415.

-5 Elia M, Stratton RJ, Holden C: Home enteral tube feeding following cerebrovascular accident. Clin Nutr 2001;20:27-30.

-6 Ickenstein GW, Stein J, Ambrosi D, Goldstein R, Horn M, Bogdahn U: Predictors of survival after severe dysphagic stroke. J Neurol 2005;252:1510-1516.

7 Crary MA: A direct intervention program for chronic neurogenic dysphagia secondary to brainstem stroke. Dysphagia 1995;10:618.
8 Huckabee M, Cannito M: Outcomes of swallowing rehabilitation in chronic brainstem dysphagia: a retrospective evaluation. Dysphagia 1999;14:93-109.

9 Basmajian JV, DeLuca CJ: Muscles Alive. Their Functions Revealed by Electromyography. Baltimore, Williams \& Wilkins, 1985.

10 Schleenbaker RE, Mainous AG: Electromyographic biofeedback for neuromuscular reeducation in the hemiplegic stroke patient: a meta-analysis. Arch Phys Med Rehabil 1993; 74:1301-1304.

11 Moreland JD, Thomson MA, Fuoco AR: Electromyographic biofeedback to improve lower extremity function after stroke: a meta-analysis. Arch Phys Med Rehabil 1998; 79:134-140.

12 Logemann J: Slikstoornissen. Onderzoek en behandeling, ed 2. Lisse, Swets \& Zeitlinger, 2000.

13 Ding R, Larson CR, Logemann JA, Rademaker AW: Surface electromyographic and electroglottographic studies in normal subjects under two swallow conditions: normal and during the Mendelsohn manuever. Dysphagia 2002;17:1-12.

14 Kahrilas PJ, Logemann JA, Krugler C, Flanagan E: Volitional augmentation of upper esophageal sphincter opening during swallowing. Am J Physiol 1991;260:G450-G456.
15 Lazarus C, Logemann JA, Gibbons P: Effects of maneuvers on swallowing function in a dysphagic oral cancer patient. Head Neck 1993;15:419-424

16 Bogaardt H: Biofeedback bij chronische bulbaire slikstoornissen. Logop Foniatr 2003; 75:226-231

17 Duchateau J, Hainaut K: Isometric or dynamic training: differential effects on mechanical properties of a human muscle. J Appl Physiol 1984;56:296-301.

18 Easterling C, Grande B, Kern M, Sears K, Shaker R: Attaining and maintaining isometric and isokinetic goals of the Shaker exercise. Dysphagia 2005;20:133-138.

19 Crary MA, Carnaby G, Groher M, Helseth E: Functional benefits of dysphagia therapy using adjunctive sEMG biofeedback. Dysphagia 2004; 19:160-164.

20 Langmore S: Endoscopic Evaluation and Treatment of Swallowing Disorders. New York, Thieme, 2001.

21 Shaker R, Kern M, Bardan E: Augmentation of deglutitive upper esophageal sphincter opening in the elderly by exercise. Am J Physiol 1997;272:1518-1522.

-22 Van Peppen RP, Kwakkel G, Wood-Dauphinee S, Hendriks HJ, Van der Wees PJ, Dekker J: The impact of physical therapy on functional outcomes after stroke: what's the evidence? Clin Rehabil 2004;18:833-862. 